\title{
Early Childhood Development: the Disability Policy and its implications for occupational therapists
}

\author{
Susan Carl Philpott, BSc OT (UCT), Dip Ad Ed (University of Natel), M Soc Sc (University of Natal), PhD \\ (Faculty of Law UWC) \\ Post-Doctoral Candidate, School of Education, University of KwaZulu Natal
}

The White Paper on the Rights of Persons with Disabilities encapsulates the vision not only for persons with disabilities in South Africa, but for every member of a diverse society. This paper discusses the vision of inclusion and mainstreaming contained in the White Paper and critiques the specific provisions for early childhood development, exploring their implications for training and practice of occupational therapists. Recommendations are made as to how these can be strengthened in achieving the vision of an inclusive society in which young children with disabilities are able to realise their potential.

Key words: children with disabilities, early childhood development, inclusion, mainstreaming, policy

\section{INTRODUCTION}

\section{Background to the policy}

The Integrated National Disability Strategy (INDS) was the first policy on disability that was promulgated in the post-apartheid era. Since then (in 2007) the South African government signed and ratified the United Nations Convention on the Rights of Persons with Disabilities (UNCRPD)' and its Optional Protocol, confirming its commitment to uphold and protect the rights of adults and children with disabilities in the country. The UNCRPD has been a significant milestone in the struggle for disability rights internationally, not because it creates any new rights in comparison to other human rights treaties, but because it spells out what is required for these rights to be realised for persons with disabilities. One of the obligations under the UNCRPD is that countries are to 'domesticate' it i.e. create their own laws and policies that give effect to its provisions within the local context. In fulfilment of this obligation, in March 2016 the White Paper on the Rights of Persons with Disabilities $^{2}$ (hereinafter the Disability Policy) was released by the South African President.

The Disability Policy includes a description of the current context as well as government's vision for adults and children with disabilities in South Africa. It identifies a rights-based, mainstreaming and life-cycle approach which is to be taken in respect of realising the rights of persons with disabilities. The Policy specifies the strategic pillars for realising these rights, as well as the roles and responsibilities of key stakeholders ${ }^{3}$.

\section{Significance of the Policy for occupational therapists}

Academics in the USA have recently been raising questions about what disability policy means in a time of change ${ }^{4}$. In South Africa, we as occupational therapists need to grapple with the question: What are the implications of the new Disability Policy in the current context? This is important to ensure that both training and practice are aligned with national priorities, as reflected in this policy.

It is recognised that the policy provisions identified here need to take cognisance of other relevant policies and strategies shaping occupational therapy practice in the field of early childhood. These include the Framework and Strategy for Disability and Rehabilitation Services in South Africa 2015-20205 and the National Integrated Early Childhood Development Policy ${ }^{6}$.

\section{Focus of the commentary, and definition of early childhood development}

As with the UNCRPD, the Disability Policy encompasses multiple aspects of the lives of persons with disabilities across the life course. In this article however, there is a particular focus on children in their earliest years i.e. provisions of the Policy relating to early childhood development (ECD). The definition of ECD contained in the Disability Policy is based on that in the Children's Act ${ }^{7}$, but instead of starting at birth, it is seen to start at the point of conception. ECD is defined as:

"The composite cognitive, emotional, physical, mental, communicational, social and spiritual development of children that takes place from conception until they enter formal schooling or reach the age of 8 years (in the case of children with developmental delays or disabilities for whom entry into formal schooling is delayed)"2:8.

The Policy ${ }^{2: 8}$ envisages ECD as encompassing a range of interventions, including:

* the promotion of planned and safe pregnancy, delivery and postnatal care;

* nutritional support for pregnant women and young children; * social protection to enable families to care for a young child;

* preparation for and assistance with parenting;

* childcare for working parents and other families needing help; and

* opportunities for young children to learn at home and with other children in the company of supportive adults, and preparation for formal schooling.

These interventions are reflected in the elements of nurturing care required by all young children prior to and after birth, as identified in the international literature viz. health, nutrition, security and safety, responsive caregiving and early learning ${ }^{8}$. The aim of this article is to identify the provisions of the Disability Policy in respect of ECD services, and their implications for training and practice of occupational therapists. 


\section{Methodology}

The information presented is based on systematic textual analysis ${ }^{9}$ of the Disability Policy, focusing specifically on provisions relating to young children. An initial review of the Policy as a whole was conducted and provisions relating to children collated and summarised. Following this process, a detailed analysis was conducted on the section of the policy relating specifically to early childhood development of children with disabilities (Pillar 4) and its implications for the training and practice of occupational therapists identified in light of the current status of the profession and of training as expressed in the recent National Forum for Rehabilitation Professionals in the Public Sector held in November $2017^{10}$.

\section{ECD-RELATED PROVISIONS OF THE DISABILITY POLICY AND IMPLICATIONS FOR OCCUPATIONAL THERAPISTS}

The following discussion begins with an outline of the overall vision and mission of the Disability Policy, which provides a context to the interventions envisaged. Thereafter the section pertaining specifically to early childhood development is synthesised.

\section{Vision of mainstreaming and inclusion}

The vision of the White Paper is "South Africa - a free and just society inclusive of all persons with disabilities as equal citizens", while its mission is "Inclusive and equitable socio-economic development."2:39

As with the UNCRPD, inclusion in the Disability Policy is regarded as a universal human right, aimed at embracing the diversity of people irrespective of differences such as race, gender or disability. It emphasises equal access and opportunities, addressing discrimination and intolerance. The Policy recognises that inclusion is not just about geographic relocation (as for example from a special to a mainstream classroom), but encompasses "a sense of belonging: feeling respected, valued for who you are; feeling a level of supportive energy and commitment from others so that you can best fully participate in society with no restrictions or limitations." ${ }^{\prime \prime 10}$. Such an understanding of inclusion is based on the premise that society - and not the individual - needs to change in order to accommodate diversity. Inclusion is thus about everybody, and impacts profoundly on the way that society is organised ".

The Policy asserts that "inclusion is the ultimate objective of mainstreaming" $2: 9$, and that mainstreaming requires application of the concept of universal design. This call for orientation of design towards use by a wide range of people including those with different impairments, without having to be specially adapted for a particular individual. Mainstreaming is seen to occur at two levels. First, it requires ensuring that disability is an element inherent in every programme or project, with persons with disabilities considered among the beneficiaries. Secondly, it requires ensuring that budget allocations are made for any reasonable accommodation measures that may be needed ${ }^{2: 42}$.

The White Paper identifies the following as some of the outcomes of its implementation ${ }^{2: 40}$ :

* persons with disabilities are accorded and enjoy their full political, human, social and economic rights on par with all other people in South Africa

* all persons with disabilities, irrespective of their age, gender, type of disability, race and economic status, participate fully and equally in mainstream social and economic life

* the rights of all persons with disabilities to live and work in safe and accessible environments, free from discrimination, harassment and persecution is upheld and persons with disabilities have access to recourse and redress in instances where these are violated

* an efficient, effective and development oriented state machinery that delivers services in an equitable manner, reports on the equitable outcome of public expenditure and delivery, and which complies with international and national human rights obligations.

The vision of inclusion articulated in the Disability Policy creates the imperative for professionals working in the disability sector, including occupational therapists, to take an active role in challenging systems and practices that perpetuate the marginalisation of young children with disabilities. Instead of limiting their role to increasing independence of the individual child (laudable though this is), occupational therapists should seek out opportunities to promote positive attitudes among service providers towards the participation of children with disabilities in ECD, and facilitate the mobilization of resources for inter-sectoral support. This must be done not 'for' parents, but alongside them, informed by an intentional process of listening and joint reflection on experiences of exclusion and the meaning of inclusion for young children and their families.

Further, therapists can be instrumental in giving practical guidance to the application of universal design principles in the context of ECD. Working alongside programme planners and developers, they can help to identify what is required for disability inclusion within each of the elements of nurturing care, and at different levels. Further, they are in a position to assess requirements for reasonable accommodation within ECD services, so that the unique support needs of individual children can be addressed. Thus occupational therapists have an important role to play in fostering an ethos of inclusion within ECD services, such that children with disabilities are welcomed and accommodated.

\section{Early Childhood Development: empowering children and their families}

Recognising that certain categories of persons with disabilities remain on the margins of service delivery and benefits, Pillar 4 of the Disability Policy focuses on the empowerment of particular groups, including children. The Policy holds that access to relevant information, early identification, community-based intervention and inclusive ECD opportunities are necessary "to unlock the potential of children with disabilities":75. The benefits of inclusion of children with disabilities in ECD as outlined in the Policy are well supported in the literature, which confirms that interventions made during this period of accelerated growth have the greatest impact on those who are most disadvantaged ${ }^{12-14}$. The Policy asserts that participation is a key mechanism to achieve empowerment, and thus emphasis is placed on supporting children's evolving capacities through opportunities to participate and to express their 'voice' from the youngest age and severest impairment ${ }^{15}$. ECD services are seen not only as a means to contribute to enabling children with disabilities to fulfil their individual potential, but also as a way of realising children's rights during early childhood and strengthening the social and economic foundation of society ${ }^{8}$.

The Policy contains three directives with respect to ECD:

\section{a) Equitable access to services}

First, there is the requirement that children with disabilities have equitable access to all ECD programmes and facilities. This means that mainstream ECD programmes and facilities are made accessible for them viz. that infrastructure, attitudes, equipment and activities do not hinder the participation of children with disabilities. Thus building plans, playgrounds, equipment, toys and ECD practitioner training must comply with universal design norms and standards ${ }^{2}$.

Accessibility is one of the Articles of the UNCRPD, aimed at enabling persons with disabilities "to live independently and participate in all aspects of life"'. It is a systemic solution, which targets all groups of persons with disabilities, in contrast to reasonable accommodation which focuses on the unique needs and situation of the individual. Elements of accessibility which need to be addressed include the environment, information and communication, attitudes and behaviour and systemic factors ${ }^{16}$. The need to implement accessibility standards is echoed by the Framework and Strategy for Disability and Rehabilitation Services 2015-2020 (Goal 4.4.4) (113. $^{5}$. 
What are the implications for training and practice of occupational therapists? Although there is a primary focus on functional limitations, it is important for therapists to be able to see the challenges of young children with disabilities within the broader context of institutional and social barriers. For example, why is a young mother reluctant to take her child with cerebral palsy to the local clinic for immunisation? Why is a child who is Deaf left to play on his own at an ECD centre? They require knowledge and skills in respect of the continuum which spans universal access, accessibility and reasonable accommodation within the context of ECD services. Further, they require insight and interpersonal skills to work with local NGOs and public sector personnel, towards building inclusive practices within the ECD sector.

\section{b) Disability specific intervention and support}

The Policy recognises that in addition to enabling environments and access to services available to the general public, children with disabilities require a range of disability specific support ${ }^{2}$. These services must focus on screening, early identification and assessment to determine individualised support programmes, language and communication development, assistive devices and technology and therapy aimed at increasing independence and social integration. This may be in the form of specialised or community-based rehabilitation, habilitation or psychosocial support services. Disability specific support also encompasses peer and family counselling and empowerment support services. This is an inter-sectoral competence, involving personnel from the departments of Health, Social Development and Education.

The Strategy and Framework for Disability and Rehabilitation Services (Goal 4.4.I) 5:13 emphasises the need to incorporate disability and rehabilitation services within priority health programmes, including maternal and child health, and child health services. This is already being done in some provinces: in the Western Cape there is a focus on the First I000 Days (spanning the period from conception until the end of the second year) and in KwaZulu Natal and the Free State, therapists are involved in Early Childhood Intervention programmes ${ }^{10}$.

What are the implications for training and practice? Recognising the critical importance of therapy aimed at addressing the unique situation of individual children, and in the current context of staff shortages, occupational therapists should seek out opportunities to de-mystify rehabilitation and equip all those who are involved in day to day contact with young children with the skills to increase their independence and social inclusion. Occupational therapists should have skills not only to provide therapy to individual children, but to train and support parents and community-level workers - including community health workers, ECD practitioners and community development workers - to do so. Further, they must stand in solidarity with parents and parent organisations, being responsive to requests for specific information or support. Occupational therapists are also in a unique position to promote child-centred approaches and inter-sectoral collaboration towards ensuring that young children with disabilities and their families receive seamless services across all sectors.

\section{c) Referral and tracking system}

In respect of young children with disabilities, the Policy mandates the development of a national integrated referral and tracking system. Elements of this are itemized in Table $I$.

The Policy makes it clear that there are several components to the tracking system viz. identification, referral, assessment, support and treatment, as well as social assistance and parental information. It is important that the process does not stop at the point of identification of developmental delays, barriers to learning or other challenges but that it directly feeds into further assessment and intervention as necessary. Again, this directive of the Policy dovetails with the Strategy and Framework for Disability and Rehabilitation Services, Goal 2 of which is to "develop an appropriate, effective and efficient referral system between all levels of care..." $5: 13$.
Table I: Elements of national integrated referral and tracking system ${ }^{2: 76}$

- Identify children at high risk of, or with developmental delays and/or disabilities through Road to Health screening programmes and refer them to relevant accessible services.

- Register all children between 0-18 on a centralized data base.

- Ensure that children with disabilities on the database are assessed and have access to an individualised developmental support and treatment programme and social assistance benefits.

- Ensure that all children with disabilities remain on this database until the age of 18 years.

- Ensure that all children with disabilities are enrolled in appropriate ECD and compulsory education programmes.

- Ensure that parents receive timeous, appropriate and ac cessible information in order for them to take decisions in the best interests of their children.

Significantly, the Policy makes reference to the use of the Road to Health Booklet as a means of identification of children requiring support. Research conducted by Orbis Africa in $2016^{17}$ found that its current usage focuses on child survival (immunisations and nutrition), rather than on the promotive, screening and referral mechanisms aimed at supporting the development of the young child. In particular, the table of developmental milestones contained in the Booklet is not routinely completed by nurses or monitored by supervision structures. As a result, this potentially valuable tool for screening is currently being under-utilised.

Within the education sector, there has been the development of a tool to assist with screening and referral viz. Screening, Identification, Assessment and Support (SIAS) ${ }^{18}$. However the focus and development of SIAS has been primarily on children of school-going age and it requires some adaptation in order to be relevant to the context of infants and young children.

In light of the requirement that identification of a child with compromised development must lead directly to support, it is necessary that services are in place and information is available for parents. And yet there are ongoing challenges of late referrals compounded by inadequate rehabilitation personnel in the public sector involved in services for children ${ }^{10}$.

Strengthening of referral systems for young children with disabilities calls for particular training and practice of occupational therapists. First, they need to be familiar with services that make up the components of nurturing care required by all young children, and know where these services are locally available. Disability Directories, as suggested by occupational therapists in the recent National Forum for Rehabilitation Professionals ${ }^{19}$, may be one means of doing so; but it is recommended that such Directories also include general services available for young children, such as toy libraries. Further, occupational therapists must be familiar with and make use of information contained in the Road to Health Booklet, particularly the developmental milestones and ideas it contains for parents to stimulate early learning of their children. Occupational therapists need to develop the skills and knowledge required to support parent programmes, including support groups.

Given the broad range of services that ECD encompasses, it is important that occupational therapists acknowledge the importance of transitions within and across services. For example, information collected on assessment of a child in an ECD centre should be communicated to the school when the child enters Grade R.

Further, there needs to be development of approaches to ECD service provision which are responsive to the local context, towards strengthening community outreach and community based services. Occupational therapists can play an important role in improving referrals up and down the chain, by contributing their own feedback within the referral system, thereby also extending knowledge and 
understanding among other service providers about the impact of early interventions on the lives of young children with disabilities.

\section{CONCLUSION}

The measure and value of any policy is in the effectiveness of its implementation. Will the vision of an inclusive society, a society in which all young children are nurtured in fulfilling of their potential, be realised? Occupational therapists have a unique role in partnering with parents, children and communities, as well as with other service providers, to ensure that young children with disabilities are cherished and have the necessary support to enable them to participate in and benefit from ECD services.

\section{ACKNOWLEDGEMENTS}

The author would like to express thanks to Dr Pam McLaren and Prof Nithi Muthukrishna for the invaluable comments on early drafts of this article.

\section{REFERENCES}

I United Nations. UN Convention on the Rights of Persons with Disabilities, 2006.

2 RSA. White Paper on the Rights of Persons with Disabilities, 2015.

3 Lead agencies responsible for specific policy directives are identified in the Implementation Matrix 20 I 5-2030 that accompanies the White Paper.

4 Schalock RL. Introduction to the Special Issue on Disability Policy in a Time of Change. Intellectual and Developmental Disabilities, 20I7; 55(4): 2I5-22.

5 Department of Health. Framework and Strategy for Disability and Rehabilitation Services in South Africa 2015-2020, 2015.

6 RSA. National Integrated Early Childhood Development Policy, 2015.

7 Children's Act 38 of 2005 s9l(I).

8 Black MM, Walker SP, Fernald LCH, Andersen CT, DiGirolamo AM, Lu C, et al. Early childhood development coming of age: science through the life course. Lancet, 2017; 389(I0064): 77-90.

9 Fairclough N. Analysing discourse: textual analysis for social research. London \& New York: Routledge, 2003.

I0 Pillay R. National Forum for Occupational Therapy in the Public Sector: Combined Public Sector Report; 2017. Copy available from author.
II Philpott S, McKenzie J. Welcoming all children: the inclusion imperative. In: Jamieson L, Berry L, Lake L, editors. South African Child Gauge. Cape Town: Children's Institute, UCT, 2017: 84-90.

12 Betts J. Inclusion of children with disabilities: the early childhood imperative. UNESCO Policy Brief on Early Childhood, 2009; 46.

I3 CSDH. Early childhood development: a powerful equalizer. Final report. Geneva: Commission on the Social Determinants of Health, WHO; 2007.

14 Shonkoff JP, Richter L, Gaag Jvd, Bhutta Z. An integrated scientific framework for child survival and early childhood development. Pediatrics, 2012; 129(2): I-13.

15 The provisions for this are spelt out in three important General Comments of the Committee on the Rights of the Child viz. CRC. General Comment No. 12: The right of the child to be heard; CRC/C/GC/I2 2009; CRC. General Comment No. 7: Implementing child rights in early childhood; CRC/C/GC/7/Rev. I 2005; CRC. General Comment No. 9: The rights of children with disabilities; CRC/C/GC/9 2007.

16 CBM. Inclusion made easy. 20 I2. Available at: https://www.cbm.org/ article/downloads/7885 I/CBM_Disability_Inclusion_-_Education. pdf Accessed 22 February, $201 \overline{8}$.

17 Orbis Africa. A review of the use of the Road to Health Booklet to support the development of children with a focus on vision. 2016.

18 Department of Education. National Strategy on Screening, Identification, Assessment and Support. 2008. Available at: https://www. thutong.doe.gov.za.

19 Occupational Therapy delegates. National Forum for Rehabilitation Professionals in the Public Sector: Feedback on profession-specific discussions. Johannesburg 2017. Copy available from author.

\section{Corresponding Author}

Sue Carol Philpott

PhilpottSue@gmail.com 